\title{
ROAD TRAFFIC ACCIDENTS, SPINAL INJURIES AND SEAT BELTS ${ }^{\star}$
}

\author{
By NoRval Watson, \\ Spinal Injuries Unit, Lodge Moor Hospital, Sheffield Io, England.
}

Seat belts have been compulsorily fitted in cars in Great Britain for about I 5 years but so far it has not been made compulsory to wear them. Despite many attempts by private members of Parliament in Britain to introduce legislation to make the wearing of seat belts compulsory, no Government has strongly supported these private bills, which have usually failed through lack of parliamentary time, and the opposition of a minority of members, whose attitude has been that the freedom of the individual is of paramount importance in a society, increasingly restricted by Government decree and social attitudes.

There is no doubt about the safety value of seat belts.

In Australia, Burke found that, after the compulsory wearing of seat belts was introduced, the reduction in spinal injuries at 27 per cent was twice as large as the reduction in other serious injuries and deaths. $\mathrm{He}$ also found that the severity of the spinal injury was reduced.

In the Strathclyde region of Scotland in I980, police reports showed that persons, not wearing seat belts, were twice as likely to be killed or seriously injured in an accident than those who wore belts, who numbered I 6 per cent of the total.

The figure of 16 per cent of accidents in which seat belts were worn contrasts with the generally accepted figure of 30\% of all journeys in which belts are worn. This would indicate that persons wearing seat belts are less likely by half to become involved in accidents than non-belt wearers, as well as being only half as likely to be killed or seriously injured, giving an overall reduction of risk from 100 per cent to 25 per cent in favour of seat belt wearers.

Most experts agree that many spinal injuries are caused by being ejected from the vehicle or by being thrown about inside the car. A recent survey reported that persons ejected were fifteen times more likely to suffer such injuries than those not ejected. Only 3 per cent of people in cars who sustained a severe neck injury wore a seat belt, 97 per cent did not.

There cannot be any doubt that the wearing of seat belts reduces the morbidity and mortality of accidents, although there will always be particular instances when the wearing of a seat belt might be contributory to the injury, as in fire, whiplash injuries, rear impact injuries where a reverse type of spinal fracture may result, and where the roof of the car is crushed downwards.

A British Medical Association and Royal College of Nursing report in I98I indicated that 700 lives would be saved and 7000 serious injuries.

* Summary of Paper read at the Meeting of the International Medical Society of Paraplegia, Stoke Mandeville Hospital, Aylesbury, England, July I98I. 
avoided in the U.K. each year if everyone in a car wore a seat belt. The cost to the health Service was $£$ I 8 million yearly to care for these victims.

I have estimated the cost to society of a spinal injury in the U.K. at between $£ 200000$ and $£ 500000$ over 30 years.

Analysis of the records of all patients with acute spinal injury admitted to this Unit during the I5 years I966-80, during which period seat belts have been compulsorily fitted in cars, but not compulsorily worn, revealed that road traffic accidents were responsible for 42 per cent of all admissions. Of these 350 road accidents, 30 per cent were motorcyclists, IO per cent were pedestrians and 60 per cent were motorists, drivers or passengers.

Further analysis of the 203 motor car accidents revealed that only one in every 12 cases of spinal injury was wearing a seat belt.

The previous statistics from Scotland in 1980 indicated that the risks of serious injury and death were reduced by 75 per cent by wearing belts, by which we might have expected an incidence of spinal injury of about 47 cases while wearing belts. Our actual figure of only I 6 injuries while wearing belts is therefore much less by 60 per cent of the projected figure, and this confirms the Australian experience that the reduction in spinal injuries while wearing belts was greater than the reduction in other serious injuries and deaths.

This justifies the attitude of the Courts who deduct up to 25 per cent of damages, where they consider that the non-wearing of a belt may have aggravated or contributed to injury or death.

When the wearing of seat belts becomes compulsory by law, the Courts might be justified in a much larger reduction in damages in people with a spinal injury, not wearing belts, than in other types of serious injury.

An analysis of the I6 patients with a spinal injury, while wearing a seat belt, revealed that five already suffered from degenerative spinal disease in which minor trauma could lead to serious cord injury, two were involved in rear impact collisions in which the seat belts were of little value, and three were travelling in soft top sports cars which overturned. In only six of the accidents were there no contributory factors, and possibly one could state that in this small number the seat belts did not give the protection that the wearer expected.

The survey clearly showed that the wearing of a seat belt resulted in a greatly reduced risk of spinal injury.

Many front seat passengers only wear belts if the driver does so, and these are the passengers who often get the most serious injuries by striking the windscreen or being ejected, as the driver is able to hold on to the wheel and brace himself for the impact.

It behoves good drivers to encourage passengers to wear seat belts by doing so themselves.

\section{REFERENCES}

Burke, D. C. (1973). Spinal Cord Injuries and Seat Belts. Medical fournal of Australia, 2, 80 I-806.

Strathclyde Police Report (1980). In the Sunday Standard Ioth May, I98I. British Medical Association and Royal College of Nursing Report: 1981. (Press Report). 